\section{A device for dispensing small animals}

\section{A. MacNEIL, M. M. GOWER and A. KUEHN Research Division Hoffmann-LaRoche Inc. Nutley, N.J. 07110}

While studying the neurophysiology of mouse-killing and frog-killing by male hooded rats, it became necessary to present a mouse or a frog in a controlled manner during an experimental program. As a result, a device was constructed to deliver a single frog or mouse automatically.

The dispenser (Fig. 1) consists of (1) a plastic tube with an inside diameter of 2-1/8 in., (2) a trap door in the shape of a paddle, (3) a lock, (4) a trip mechanism, (5) a spring mechanism to open the trap door, (6) a mounting plate, and (7) the housing. ${ }^{1}$ The tube is attached to the corner of the housing where a slot was cut to accommodate the trap door. The trap door is attached to the top of a telephone dial mechanism which had the finger wheel removed. Part of the finger stop of the dial mechanism was cut off, and the remaining portion was covered with a rubber grommet to serve as a stop (8) for the trap door. A telephone dial was used because the return speed of the dial is regulated, thus preventing the trap door from slamming loudly against the stop. The trip mechanism is an air-release piston which is used for operating a camera shutter. A pneumatic piston was chosen to avoid artifacts that an electrical solenoid would create in electrophysiological recordings. The entire housing fits on top of the rat's home cage when the lid of the cage is raised.

To operate the dispenser, an air hose from a remote solenoid valve is connected to the piston inlet. At a command from programming equipment, the valve opens and allows compressed air into the piston. The
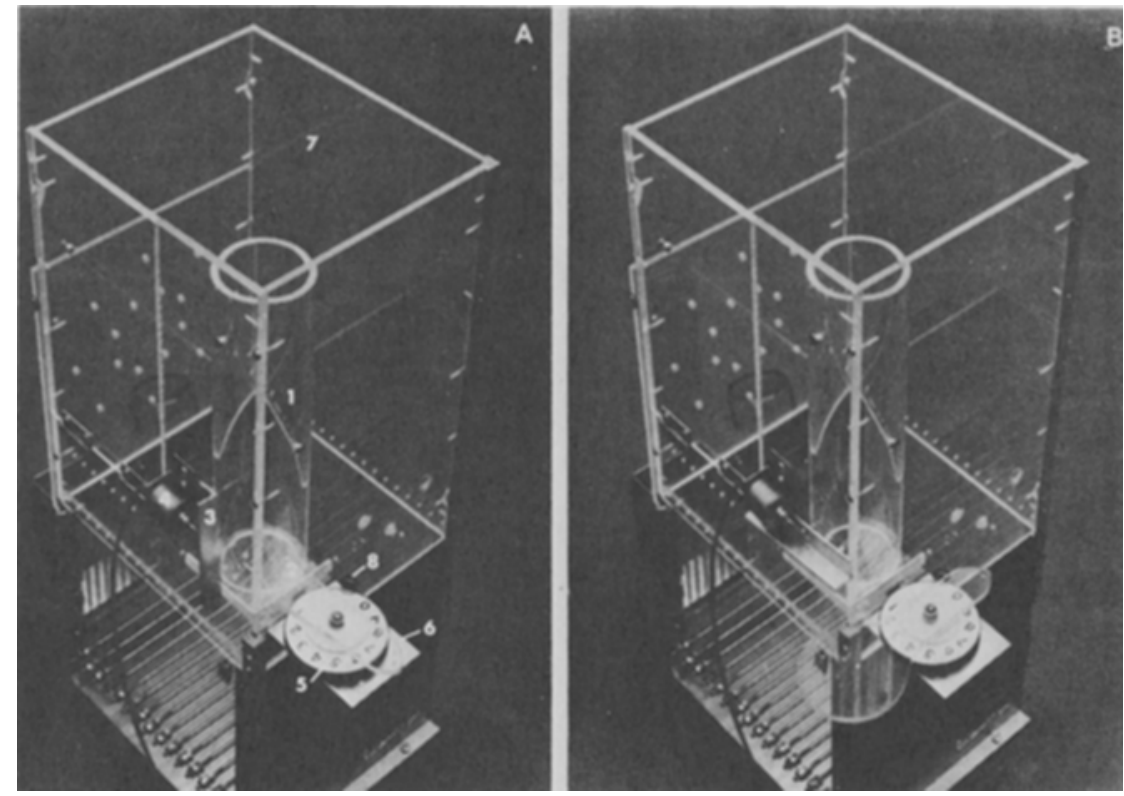

Fig. 1. (A) The dispenser is locked with the trap door in the closed position. (B) The lock has been tripped, and the trap door is shown in the open position. See text for a description of the numbered parts.

piston rod then extends and rotates the lock, after which the trap door swings open. The dispenser may also be operated manually with a squeeze bulb.

No difficulties have been encountered when dispensing mice. Frogs, however, will occasionally leap out or will remain wedged at the base of the tube after the trap door opens. Thus, when dispensing a frog, an 80-g cylindrical weight (not shown) is placed on top of the frog, not only to keep him in the tube, but also to ensure that he drops into the rat's cage. A piece of string tied between the weight and the top of the tube prevents the weight from dropping beyond the end of the tube.

The dispenser has operated reliably during an experiment in which evoked potentials were recorded from rats before and after a kill. Approximately 80 frogs were dispensed without malfunctions.

\section{NOTE}

1. Parts may be obtained from the following suppliers: telephone diat-(new) Barry Electronics. 512 Broadway, New York, N.Y. 10012, Catalog No. WE6A \$4.95; (used) Fair Radio Sales Co., P.O. Box 1105, 1016 E. Eureka St. Lima, Ohio $45802, \$ 1.50 ;$ Rowi shutter release-Edmund Scientific Co. 801 Edscorp Bldg., Barrington, N.J. 08007. $\$ 8.75$ (or local camera store). 